\title{
TDP-43 Toxicity Proceeds via Calcium Dysregulation and Necrosis in Aging Caenorhabditis elegans Motor Neurons
}

\author{
Dina Aggad, ${ }^{1}$ Julie Vérièpe, ${ }^{1,2}$ Arnaud Tauffenberger, ${ }^{1,2}$ and ${ }^{\circledR}$ J. Alex Parker ${ }^{1,2,3}$ \\ ${ }^{1}$ CRCHUM, Départements de 2Pathologie et Biologie Cellulaire, and ${ }^{3}$ Neurosciences, Université de Montréal, Montréal, Québec H1Y 3L1, Canada
}

\begin{abstract}
Amyotrophic lateral sclerosis (ALS) is a heterogeneous disease with either sporadic or genetic origins characterized by the progressive degeneration of motor neurons. At the cellular level, ALS neurons show protein misfolding and aggregation phenotypes. Transactive response DNA-binding protein 43 (TDP-43) has recently been shown to be associated with ALS, but the early pathophysiological deficits causing impairment in motor function are unknown. Here we used Caenorhabditis elegans expressing mutant TDP- $43^{\mathrm{A} 315 \mathrm{~T}}$ in motor neurons and explored the potential influences of calcium $\left(\mathrm{Ca}^{2+}\right)$. Using chemical and genetic approaches to manipulate the release of endoplasmic reticulum (ER) Ca ${ }^{2+}$ stores, we observed that the reduction of intracellular $\mathrm{Ca}^{2+}\left(\left[\mathrm{Ca}^{2+}\right]_{\mathrm{i}}\right)$ rescued age-dependent paralysis and prevented the neurodegeneration of GABAergic motor neurons. Our data implicate elevated $\left[\mathrm{Ca}^{2+}\right]_{\mathrm{i}}$ as a driver of TDP-43-mediated neuronal toxicity. Furthermore, we discovered that neuronal degeneration is independent of the executioner caspase CED-3, but instead requires the activity of the $\mathrm{Ca}^{2+}$-regulated calpain protease TRA-3, and the aspartyl protease ASP-4. Finally, chemically blocking protease activity protected against mutant TDP- $43^{\mathrm{A} 315 \mathrm{~T}}$-associated neuronal toxicity. This work both underscores the potential of the C. elegans system to identify key targets for therapeutic intervention and suggests that a focused effort to regulate $\mathrm{ER} \mathrm{Ca}^{2+}$ release and necrosis-like degeneration consequent to neuronal injury may be of clinical importance.
\end{abstract}

Key words: ALS; C. elegans; calcium; ER; necrosis; TDP-43

\section{Introduction}

Amyotrophic lateral sclerosis (ALS) is a fatal neurodegenerative disease characterized by the selective loss of both upper and lower motor neurons in the cortex and spinal cord (Wijesekera and Leigh, 2009). ALS is an age-dependent, rapidly progressive disease with life expectancy typically being between 2 and 5 years after onset. Thanks to recent genetic advances, causative mutations for ALS have been discovered in over a dozen genes (Renton et al., 2014), including one encoding transactive response DNAbinding protein 43 (TDP-43; Kabashi et al., 2008) among others.

Evidence is mounting that pathways regulating protein degradation may influence ALS pathogenesis (Blokhuis et al., 2013). We previously reported that mutant TDP- $43^{\mathrm{A} 315 \mathrm{~T}}$ proteins expressed in Caenorhabditis elegans motor neurons are susceptible to misfolding, leading to insolubility, aggregation (Vaccaro et al., 2012a), and activation of the endoplasmic reticulum (ER) unfolded protein response (UPR ${ }^{\mathrm{ER}}$; Vaccaro et al., 2012b, 2013).

Received June 12, 2013; revised July 24, 2014; accepted July 28, 2014.

Author contributions: D.A., J.V., A.T., and J.A.P. designed research; D.A. and J.V. performed research; A.T. contributed unpublished reagents/analytic tools; D.A., J.V., and J.A.P. analyzed data; D.A. and J.A.P. wrote the paper.

Some strains were provided by the Caenorhabditis Genetics Center, which is funded by the National Institutes of Health Office of Research Infrastructure Programs (P40 0D010440). This research was supported by the CHUM Foundation, the ALS Society of Canada, the Canadian Institutes of Health Research, the Fonds de Recherche Santé Québec, the Muscular Dystrophy Association (U.S.), and the Congressionally Directed Medical Research Program Amyotrophic Lateral Sclerosis Research Program (U.S.), and a Canadian Institutes of Health Research New Investigator Award to J.A.P. We thank S. Peyrard for technical help.

Correspondence should be addressed to J. Alex Parker, CRCHUM, 900 St-Denis, Tour Viger, R09.440, Montreal, QC H2X 0A9, Canada. E-mail: ja.parker@umontreal.ca.

DOI:10.1523/JNEUROSCI.2495-13.2014

Copyright $\odot 2014$ the authors $\quad 0270-6474 / 14 / 3412093-11 \$ 15.00 / 0$
Induction of the UPR ${ }^{\mathrm{ER}}$ by mutant TDP-43 suggests that the capacity of the ER to properly fold proteins may be exceeded, leading to cellular dysfunction and death (Walker and Atkin, 2011).

The ER constitutes a $\mathrm{Ca}^{2+}$ store whose uptake and release are extensively regulated to maintain cellular $\mathrm{Ca}^{2+}$ homeostasis, and disrupted ER function can induce $\mathrm{Ca}^{2+}$ depletion (Burdakov and Verkhratsky, 2006). Altered $\mathrm{Ca}^{2+}$ homeostasis has been investigated as a mechanism to distinguish motor neurons that are vulnerable or resistant to degeneration in ALS (Palecek et al., 1999; Vanselow and Keller, 2000). Indeed, ALS-vulnerable motor neurons in mice display $\mathrm{Ca}^{2+}$ buffering capacities that are five to six times lower compared with those found in ALS-resistant oculomotor neurons (Vanselow and Keller, 2000), while a more recent study has shown that altered $\mathrm{Ca}^{2+}$ buffering may be a risk factor for SOD-1 toxicity (von Lewinski et al., 2008).

We investigated the role of cellular $\mathrm{Ca}^{2+}$ balance in our TDP-43 models to learn more about the mechanisms of $\mathrm{Ca}^{2+}$ mediated cellular demise. We report that a null mutation in cal-

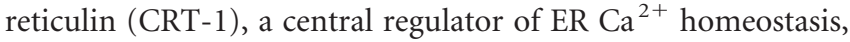
suppresses both paralysis and the neurodegeneration caused by mutant TDP- $43^{\mathrm{A} 315 \mathrm{~T}}$ in motor neurons. Furthermore, deletion of the $\mathrm{Ca}^{2+}$ binding ER protein calnexin (CNX-1), the ER $\mathrm{Ca}^{2+}$ release channels UNC-68 (ryanodine receptor), or ITR-1 (inositol 1,4,5 triphosphate receptor) suppressed TDP-43 toxicity. Consistently, pharmacological manipulations modulating ER $\mathrm{Ca}^{2+}$ release and/or uptake suppressed TDP-43 toxicity. Downstream from perturbed $\mathrm{Ca}^{2+}$ homeostasis, we discovered that mutations in the $\mathrm{Ca}^{2+}$-regulated calpain protease TRA-3 and aspartyl protease ASP-4 also suppressed TDP-43 toxicity. 
Our findings suggest that the regulation, and possibly release, of $\mathrm{ER} \mathrm{Ca}^{2+}$ stores are required for neurotoxicity of TDP-43 in $C$. elegans. It is generally believed that caspase-driven neuronal apoptosis is an underlying pathogenic mechanism in many lateonset neurodegenerative diseases including ALS (Martin, 1999), but the executioner caspase CED-3 is dispensable for neurodegeneration in our TDP-43 model. Instead, the involvement of calpain and aspartyl proteases is more similar to necrosismediated cell death (Syntichaki et al., 2002). We propose that misfolded mutant TDP-43 increases $\left[\mathrm{Ca}^{2+}\right]_{\mathrm{i}}$ by disrupting ER function and activates calpain proteases, which in turn activates killer aspartyl proteases, leading to cell destruction.

\section{Materials and Methods}

C. elegans strains and methods. Standard culturing and genetic methods were used (Stiernagle, 2006). Animals were maintained at $20^{\circ} \mathrm{C}$ unless otherwise indicated. Unless otherwise stated, the strains used in this study were obtained from the Caenorhabditis Genetics Center (University of Minnesota, Minneapolis, MN) and include the following: asp4(ok2693), ced-3(ok2734), cnx-1(nr2009), cnx-1(nr2010), crt-1(bz30), crt-1(jh101), itr-1(sa73), kbIs7 [nhx-2p::rde-1 + rol-6(su1006)], kzIs20[pDM\#715(hlh-1p::rde-1) + pTG95(sur-5p::nls::GFP)], oxIs12 $[$ unc-47p::GFP + lin-15(+)], rde-1(ne219), sid-1(pk3321), tra3(ok2207), uIs69 [pCFJ90(myo-2p::mCherry) + unc-119p::sid-1], and unc-68(e540). Genetic crosses generated transgenic/mutant combinations, and the presence of transgenes and mutations was confirmed by PCR, visible markers, sequencing, or a combination thereof.

Transgenic lines expressing mutant TDP-43 ${ }^{\mathrm{A} 315 \mathrm{~T}}$, wild-type TDP-43 (TDP-43 ${ }^{\mathrm{WT}}$ ), unc-47p::GFP; TDP-43 ${ }^{\mathrm{A} 315 \mathrm{~T}}$, and $u n c-47 p:: \mathrm{GFP}$; TDP$43^{\mathrm{WT}}$ were previously described (Vaccaro et al., 2012a) and created as follows: human cDNAs for TDP-43 ${ }^{\mathrm{WT}}$ and TDP-43 ${ }^{\mathrm{A} 315 \mathrm{~T}}$ (a gift from Dr. Guy Rouleau, McGill University, Montreal, QC, Canada) were amplified by PCR and cloned into the Gateway vector pDONR221 following the manufacturer's protocol (Invitrogen). Multisite Gateway recombination was performed with the pDONR TDP-43 clones along with clones containing the unc-47 promoter (a gift from Dr. Erik Jorgensen, University of Utah, Salt Lake City, UT; and Dr. Marc Hammarlund, Yale University, New Haven, CT), the unc-54 3' UTR plasmid pCM5.37 (Addgene plasmid 17253; a gift from Dr. Geraldine Seydoux, Johns Hopkins University, Baltimore, MD), and the destination vector pCFJ150 (Addgene plasmid 19329; a gift from Dr. Erik Jorgensen, University of Utah) to create $u n c-47 p:: T D P-43$ expression vectors. Transgenic lines were created by microinjection of unc-119(ed3) worms, multiple lines were generated, and strains behaving similarly were kept for further analysis. Transgenes were integrated by UV irradiation, and lines were outcrossed to wild-type N2 worms five times before use. Several strains showing comparable phenotypes and transgene expression levels were kept and the strains used in this study include the following: $x q I s 132\left[u n c-47 p:: T D P-43^{W T}\right.$; unc-119(+)] and xqIs133[unc-47p::TDP-43 ${ }^{\text {A315T; }}$ unc-119(+)].

Pharmacological treatment. All chemicals were obtained from SigmaAldrich. Dantrolene and thapsigargin were dissolved in DMSO and added to agar plate to final concentrations of $10 \mu \mathrm{M}$ and $3 \mu \mathrm{g} / \mathrm{ml}$, respectively. EGTA was dissolved in $1 \mathrm{~N} \mathrm{NaOH}$ and was added to agar plates to a final concentration of $0.5 \mathrm{mM}$. MDL-28170 was dissolved in DMSO and added to agar plate to a final concentration of $20 \mu \mathrm{M}$.

Paralysis assay. Worms were grown at $20^{\circ} \mathrm{C}$ on standard Nematode Growth Media (NGM) plates with or without compounds (30 animals/ plate, by triplicates) and scored daily for movement. Animals were scored as paralyzed if they failed to move upon prodding with a worm pick. Failure to move their head to touch and the absence of pharyngeal pumping was scored as dead. Statistical analysis was performed using GraphPad Prism software (log-rank Mantel-Cox test).

Neurodegeneration assay. Worms (unc-47p::GFP; TDP-43 ${ }^{\mathrm{A} 315 \mathrm{~T}}$ or unc-47p::GFP; TDP-43 ${ }^{\mathrm{WT}}$, with or without additional mutations listed above) were grown at $20^{\circ} \mathrm{C}$ on standard NGM plates with or without compounds. Young adult worms were transferred onto seeded NGM plates (with or without compounds), and were selected at days 1, 5, and 9 of adulthood (100 animals/treatment). Live worms were placed on a
2\% agarose pad containing $5 \mathrm{~mm}$ levamisole in M9 medium to immobilize the worms. Worms were observed under fluorescence microscopy (Leica 6000 microscope) and scored for gaps or breaks in the processes of GABAergic neurons. The mean and SEM were calculated, and ANOVA with Bonferroni correction were used for statistical analyses.

RNA interference experiments. RNA interference (RNAi)-treated strains were fed Escherichia coli (HT115) containing an empty vector (EV) or an RNAi clone corresponding to the gene of interest indicated above. All RNAi clones were from the ORFeome RNAi library (Open Biosystems). RNAi experiments were performed at $20^{\circ} \mathrm{C}$. Worms were grown on NGM enriched with $1 \mathrm{~mm}$ isopropyl- $\beta$-D-thiogalactopyranoside. All RNAi paralysis tests were performed using a TDP- $43^{\mathrm{A} 315 \mathrm{~T}}$; $u n c-47 p:$ GFP in conjunction with the appropriate mutation and transgenes for tissue-specific silencing in neurons, intestine, or muscle cells based on strains TU3401, VP303, or NR350, respectively. To minimize developmental effects, L4 worms were grown on plates with RNAi bacteria and assayed for paralysis as adults. Worms were transferred every $2 \mathrm{~d}$.

Western blot analysis. Synchronized populations of worms expressing TDP- 43 were grown at $20^{\circ} \mathrm{C}$ on standard NGM plates with or without compounds ( 15 plates/treatment). Immunoblot analysis of protein levels was performed on whole-animal extracts prepared by washing animals in M9 medium to remove adherent bacteria. The pellets were placed at $-80^{\circ} \mathrm{C}$ overnight and homogenized in $1 \mathrm{ml} / \mathrm{g}$ RIPA buffer $(150 \mathrm{~mm}$ $\mathrm{NaCl}, 50 \mathrm{~mm}$ Tris, $\mathrm{pH}$ 7.4, $1 \%$ Triton $\mathrm{X}-100,0.1 \%$ SDS, $1 \%$ sodium deoxycholate) plus $0.1 \%$ protease inhibitors $(10 \mathrm{mg} / \mathrm{ml}$ leupeptin, 10 $\mathrm{mg} / \mathrm{ml}$ pepstatin A, $10 \mathrm{mg} / \mathrm{ml}$ chymostatin; $1: 1000)$. Pellets were sonicated and centrifuged at $16,000 \times g$. Supernatants were collected and were saved as the total fraction. Protein concentrations were determined by the Quick Start Bradford Protein Assay (Bio-Rad). Supernatants, 50 $\mu \mathrm{g} /$ well, were subjected to SDS-PAGE (10\%) and transferred to nitrocellulose membranes (Bio-Rad). The immunoblotting analyses were performed using the following antibodies: rabbit anti-TDP-43 (1:1000; Proteintech) and mouse anti-actin (1:20,000 for worms; MP Biomedicals). Proteins were visualized using peroxidase-conjugated secondary antibodies and ECL Western Blotting Substrate (Thermo Scientific). Densitometry was performed with Photoshop (Adobe).

\section{Results}

\section{Genetic manipulation of $\left[\mathrm{Ca}^{2+}\right]$ suppresses TDP-43 toxicity in motor neurons}

CRT-1 is a $\mathrm{Ca}^{2+}$ binding/storing protein of the ER that serves both as a molecular chaperone and as a central regulator of $\mathrm{Ca}^{2+}$ homeostasis (Michalak et al., 1999). Worms expressing mutant TDP-43 in their motor neurons show age-dependent motility defects, leading to paralysis and neurodegeneration (Vaccaro et al., 2012a). To investigate the role of $\mathrm{Ca}^{2+}$ balance in TDP-43 neuronal toxicity, we constructed $c r t-1(b z 30)$; TDP-43 ${ }^{\mathrm{A} 315 \mathrm{~T}}$ and crt-1(jh101); TDP-43 ${ }^{\mathrm{A} 315 \mathrm{~T}}$ strains, and scored them for paralysis. We observed a significant reduction in the rate of paralysis for crt-1(bz30); TDP-43 ${ }^{\mathrm{A} 315 \mathrm{~T}}$ and crt-1(jh101); TDP-43 ${ }^{\mathrm{A} 315 \mathrm{~T}}$ animals compared with control TDP-43 ${ }^{\mathrm{A} 315 \mathrm{~T}}$ transgenics (Fig. 1A). Focusing on $c r t-1(b z 30)$; TDP-43 ${ }^{\mathrm{A} 315 \mathrm{~T}}$, we also observed a significant rate of motor neuron degeneration compared with control TDP-43 ${ }^{\mathrm{A} 315 \mathrm{~T}}$ transgenics (Fig. $1 B$ ).

In the ER, calreticulin works in conjunction with $\mathrm{CNX}-1$ to execute chaperone functions and mediate cellular $\mathrm{Ca}^{2+}$ homeostasis (Krause and Michalak, 1997). Given the functional and structural similarities between the two proteins, we tested whether calnexin, encoded by $c n x-1$ in C. elegans, also influenced TDP-43 toxicity. We observed that introduction of the loss of function mutations $c n x-1$ (nr2009) or $c n x-1$ (nr2010) into mutant TDP-43 ${ }^{\mathrm{A} 315 \mathrm{~T}}$ transgenics led to a significant decrease in paralysis compared with control TDP-43 ${ }^{\mathrm{A} 315 \mathrm{~T}}$ transgenics (Fig. 1A). Focusing on $c n x-1$ (nr2010); TDP-43 ${ }^{\mathrm{A} 315 \mathrm{~T}}$, we also observed a sig- 
A

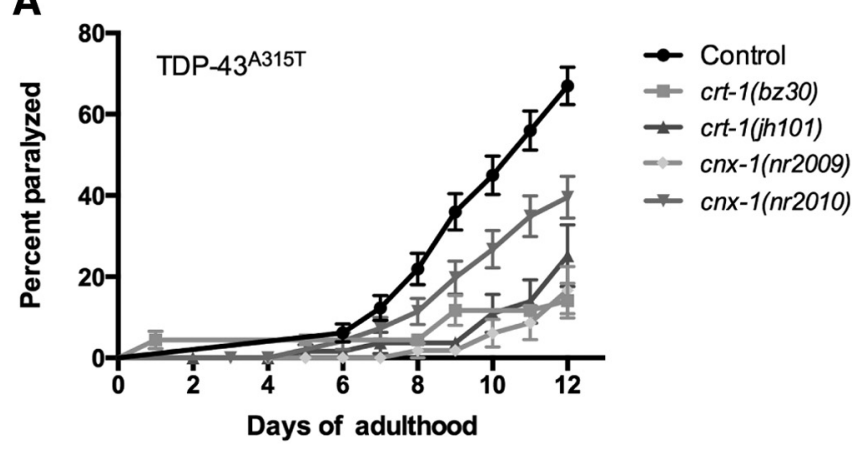

C

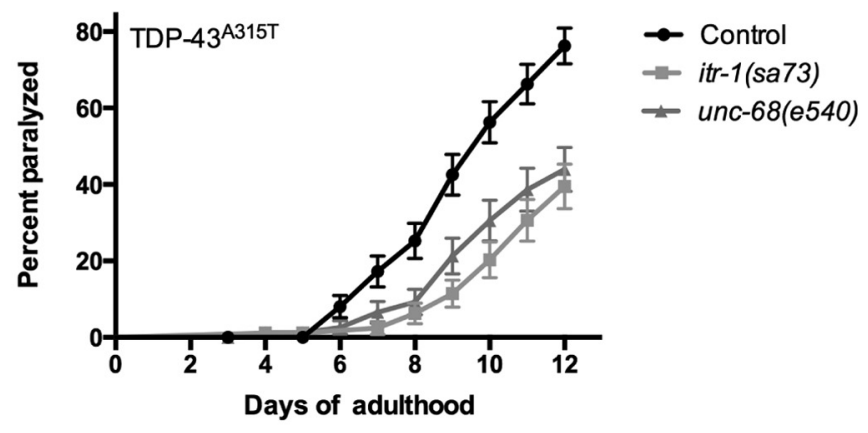

B

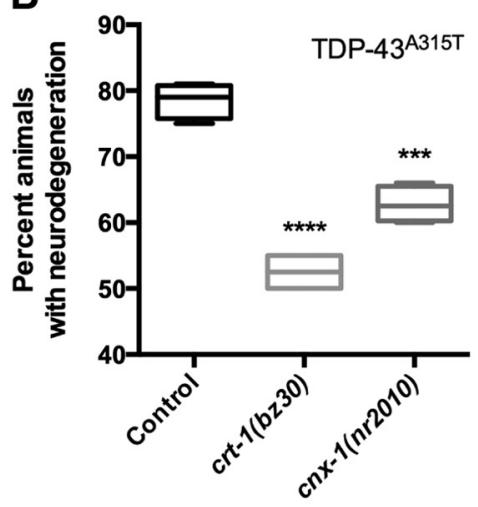

D

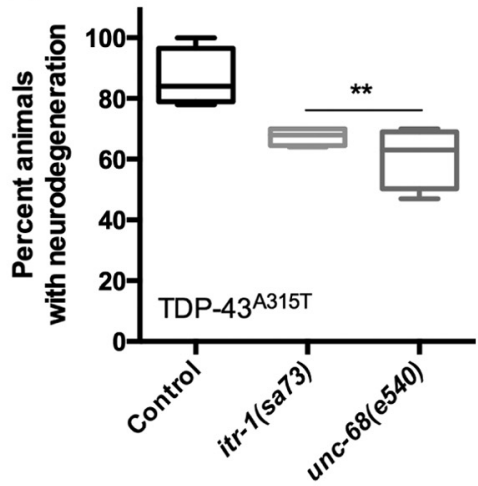

E

TDP-43 ${ }^{\text {A315T }}$
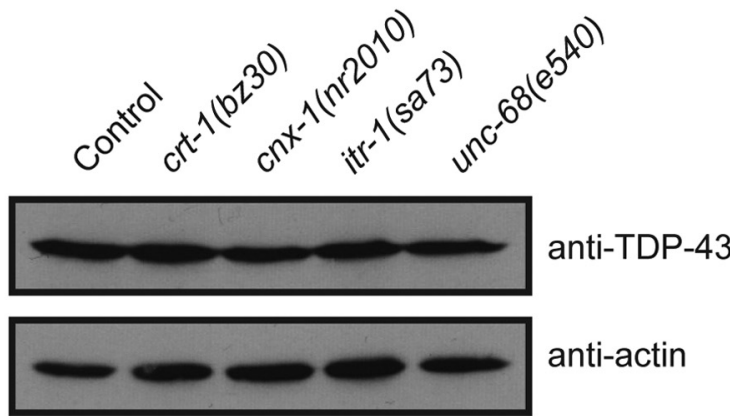

anti-actin

Figure 1. Genes regulating ER calcium release promote TDP-43 neuronal toxicity. $A$, Null mutations in cnx-1 or crt-1 suppress age-dependent paralysis caused by TDP-43 ${ }^{\mathrm{A3} 15 \mathrm{~T}}$ compared with transgenic TDP-43 ${ }^{\text {A315T }}$ controls. $p<0.0001$ for TDP-43 ${ }^{\text {A315T; }}$; nx -1 (nr2009) versus TDP-43 ${ }^{\text {A315T; }} p=0.0002$ for TDP-43 ${ }^{\text {A315T }}$; $\left(n x-1\right.$ (nr2010) versus TDP-43 ${ }^{\text {A315T; }} p<0.0001$ for TDP-43 ${ }^{\text {A315T; }}$ crt-1(bz30) versus TDP-43 ${ }^{\text {A315T }} ; p<0.0001$ for TDP-43 ${ }^{\text {A315T; }}$ crt-1(jh101) versus TDP-43 ${ }^{\text {A315T }}$. TDP-43 ${ }^{\text {A315T }}, n=114 ;$ TDP-43 ${ }^{\text {A315T }} ;\left(n n x-1\right.$ (nr2009), $n=76 ;$ TDP-43 ${ }^{\text {A315T; }}$; $n n x-1$ (nr2010), $n=98$;

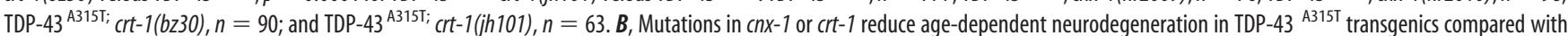
TDP-43 ${ }^{\text {A315T }}$ control animals. ${ }^{* * *} p<0.001$ versus TDP-43 ${ }^{\text {A315T }}$ at day $9 ;{ }^{* * * *} p<0.0001$ versus TDP-43 ${ }^{\text {A315T }}$ at day 9 . C, Null mutations in unc-68 and itr- 7 reduce TDP-43 $3^{\text {A315T }}$-mediated paralysis

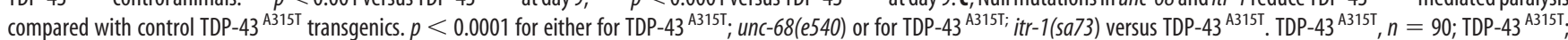
itr-1(sa73), $n=88$; and TDP-43 ${ }^{\text {A315T; }}$; unc-68(e540), $n=84$. D, Degeneration of motor neurons is reduced in adult day 9 TDP- $43^{\text {A315T }}$ transgenics compared with controls. ${ }^{* *} p<0.01$ versus TDP-43 ${ }^{A 315 T}$ at day 9. E, Western blotting with a human anti-TDP-43 antibody revealed comparable levels of protein expression in all strains.

nificant decrease of motor neuron degeneration compared with control TDP-43 ${ }^{\mathrm{A} 315 \mathrm{~T}}$ transgenics (Fig. 1B).

To complete the genetic investigation of cellular $\mathrm{Ca}^{2+}$ balance, we tested the following two other genes involved in ER regulation of $\left[\mathrm{Ca}^{2+}\right]_{\mathrm{i}}$ : the $\mathrm{ER} \mathrm{Ca}^{2+}$ release channel inositol triphosphate receptor channel InsP3R, encoded by itr-1 (Dal Santo et al., 1999), and the ER $\mathrm{Ca}^{2+}$ release channel ryanodine receptor channel RyR, encoded by unc-68 (Maryon et al., 1996). We then investigated the effects of mutations in the InsP3R and RyR genes on TDP-43 ${ }^{\mathrm{A} 315 \mathrm{~T}}$-mediated paralysis and motor neuron degeneration. Similar to the disruption of calnexin and calreticulin function, itr-1(sa73); TDP-43 ${ }^{\mathrm{A} 315 \mathrm{~T}}$ and $u n c-68(e 540)$; TDP-43 ${ }^{\mathrm{A} 315 \mathrm{~T}}$ strains displayed significantly reduced paralysis and motor neuron degeneration phenotypes compared with TDP-43 ${ }^{\mathrm{A} 315 \mathrm{~T}}$ controls (Fig. 1C,D). To confirm that the suppression of TDP-43 ${ }^{\mathrm{A} 315 \mathrm{~T}}$ neuronal toxicity was not due to transgene effects, we quantified the level of TDP-43 protein expression by immunoblotting and observed no difference in protein levels for TDP-43 in combination with any of the mutations (Fig. 1E).

Pharmacological modulation of $\left[\mathrm{Ca}^{2+}\right]_{\mathrm{i}}$ regulates TDP$43^{\mathrm{A} 315 \mathrm{~T}}$ toxicity in motor neurons

To confirm that altering $\left[\mathrm{Ca}^{2+}\right]_{\mathrm{i}}$ levels in turn regulates TDP-43 toxicity, we turned to a complementary approach by using chemical reagents to manipulate $\mathrm{ER} \mathrm{Ca}^{2+}$ release and/or uptake. We first treated TDP-43 ${ }^{\mathrm{A} 315 \mathrm{~T}}$ mutants with EGTA, a $\mathrm{Ca}^{2+}$-specific 
A

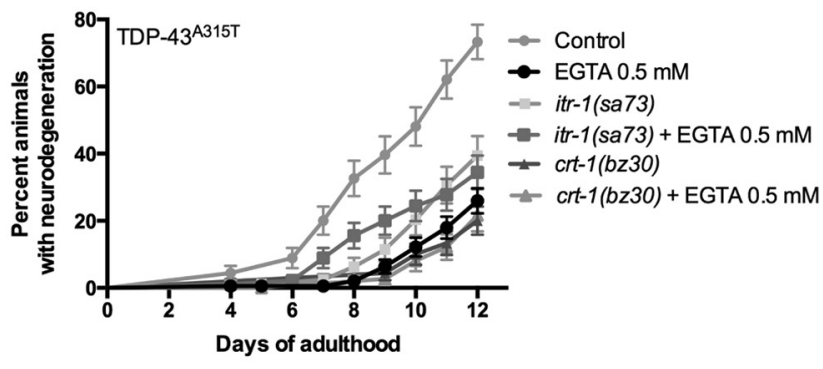

C

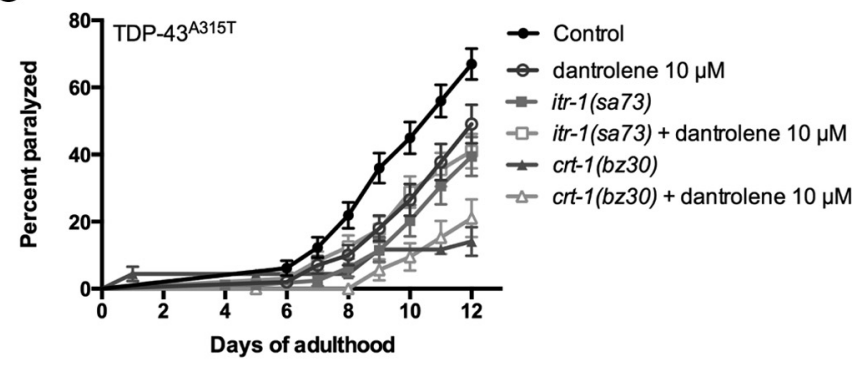

B

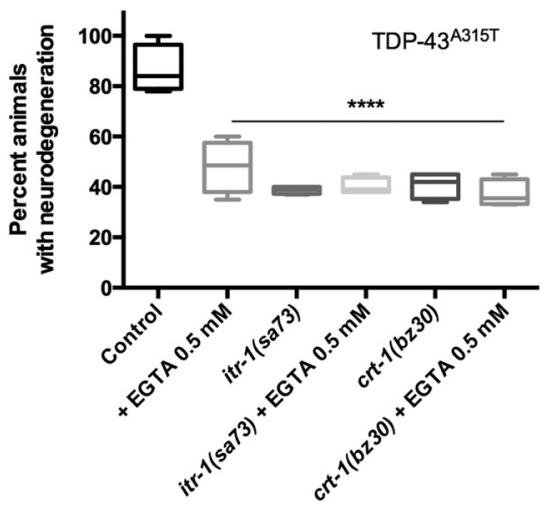

D

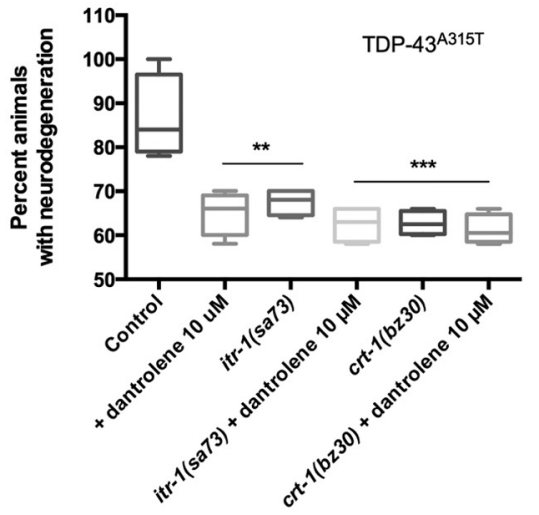

E

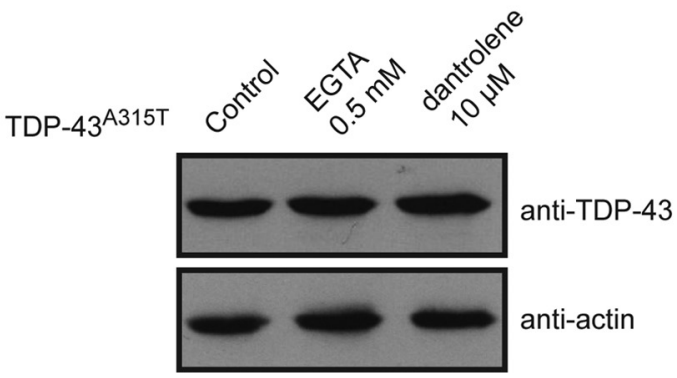

Figure 2. Pharmacological manipulation of $\left[\mathrm{Ca}^{2+}\right]_{\mathrm{i}}$ reduces TDP-43 neuronal toxicity. $A, \mathrm{TDP}-43^{\mathrm{A} 315 \mathrm{~T}}$ transgenics treated with EGTA showed significantly less paralysis compared with untreated controls $\left(p<0.0001\right.$ versus TDP-43 $\left.{ }^{\mathrm{A} 315 \mathrm{~T}}\right)$. The protective effect of EGTA was not additive to the suppression of TDP-43-mediated paralysis by mutation in either crt- 1 or itr-1. $p=0.8470$ versus TDP-43 ${ }^{\text {A315T }} ;$ crt-1 (bz30); and $p=0.7817$ versus TDP-43 ${ }^{\text {A315T }} ;$ itr-1(sa73). TDP-43 ${ }^{\text {A315T }}, n=90 ;$ TDP-43 $^{\text {A315T }}+$ EGTA, $n=181 ;$ TDP-43 $^{\text {A315T }} ;$ itr-1(sa73), $n=90 ;$ TDP-43 ${ }^{\text {A315T }} ;$ itr-1(sa73) + EGTA, $n=90 ;$ TDP-43 $^{\text {A315T }}$; crt-1(bz30), $n=90 ;$ TDP-43 ${ }^{\text {A315T }}$; crt-1(bz30) + EGTA, $n=90$. B. Degeneration of motor neurons in TDP-43 ${ }^{\text {A315T }}$ animals at day 9 of adulthood was reduced to comparable levels in TDP- $43^{\mathrm{A3} 15 \mathrm{~T}}$ transgenics treated with EGTA alone or in combination with mutations in crt-1 or itr-1. ${ }^{* * * *} p<0.0001$ versus TDP- $43^{\text {A315T }}$ at day 9. C, Treatment with dantrolene suppressed TDP-43 ${ }^{\text {A315T }}$-mediated paralysis compared with untreated control animals $\left(p=0.0031\right.$ versus TDP-43 ${ }^{\text {A315T }}$. Suppression of TDP-43 ${ }^{\text {A315T }}$-mediated paralysis by crt- 1 or itr- 1 was not

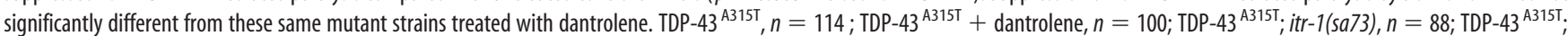

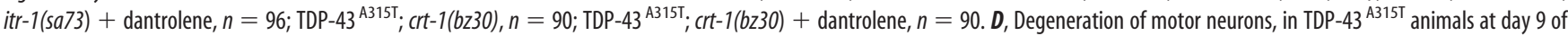
adulthood was reduced to similar levels in TDP- $43^{\mathrm{A3} 15 \mathrm{~T}}$ transgenics treated with dantrolene alone or in combination with mutations for crt- 1 or itr- $1 .{ }^{* *} p<0.01$ versus TDP-43 ${ }^{\mathrm{A3} 15 \mathrm{~T}}$ at day 9 ; ${ }^{* * *} p<$ 0.001 versus TDP-43 ${ }^{\mathrm{A} 315 \mathrm{~T}}$ at day $9 . E$, TDP-43 protein expression was unchanged by culture conditions with EGTA or dantrolene.

chelator, and observed a clear reduction in the rate of paralysis and neurodegeneration compared with untreated TDP-43 ${ }^{\mathrm{A} 315 \mathrm{~T}}$ transgenics (Fig. 2A,B). Additionally, EGTA did not further suppress paralysis and neurodegeneration in $c r t-1(b z 30)$; TDP$43^{\mathrm{A} 315 \mathrm{~T}}$ or $i t r-1$ (sa73); TDP-43 ${ }^{\mathrm{A3} 15 \mathrm{~T}}$ strains (Fig. $2 \mathrm{~A}, \mathrm{~B}$ ), suggesting that $c r t$ - , itr-1, and EGTA use a common mechanism to reduce TDP-43 toxicity, namely reduced $\left[\mathrm{Ca}^{2+}\right]_{\mathrm{i}}$.

We next tested whether $\mathrm{Ca}^{2+}$ derived from ER stores might contribute to the progressive paralysis caused by mutant TDP- 43 . We treated TDP-43 ${ }^{\mathrm{A} 315 \mathrm{~T}}$ mutants with dantrolene, a reagent that specifically inhibits $\mathrm{Ca}^{2+}$ release from ER stores (Song et al.,
1993). In dantrolene-treated animals, paralysis and neurodegeneration were markedly reduced consistent with the hypothesis that $\mathrm{ER} \mathrm{Ca}^{2+}$ stores contribute to TDP-43 neuronal toxicity (Fig. $2 C, D)$. Dantrolene treatment did not further suppress paralysis and neurodegeneration phenotypes caused by TDP-43 ${ }^{\mathrm{A} 315 \mathrm{~T}}$ in crt-1(bz30) and itr-1(sa73) mutants, suggesting a shared mechanism of action (Fig. 2C,D). The suppression of TDP-43 toxicity by EGTA and dantrolene were not due to reduced transgene expression since similar levels of TDP-43 protein expression were detected by immunoblotting in treated and untreated TDP-43 transgenics (Fig. 2E). 
A

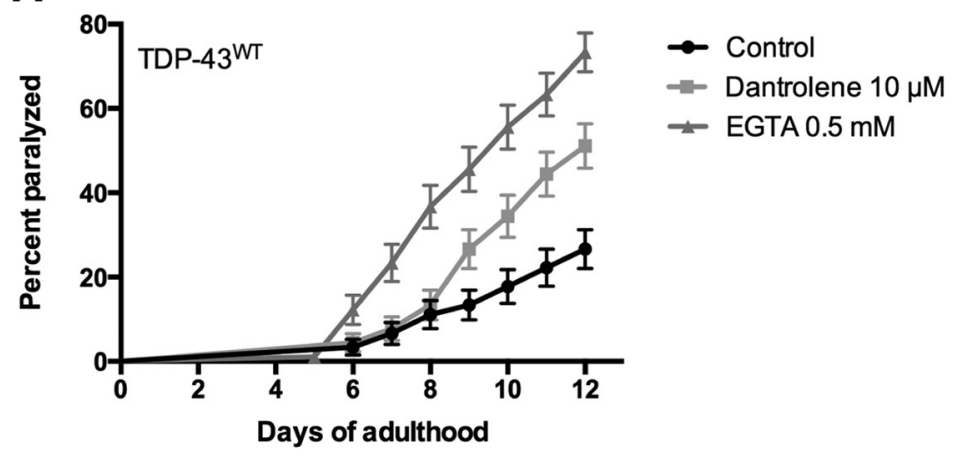

B

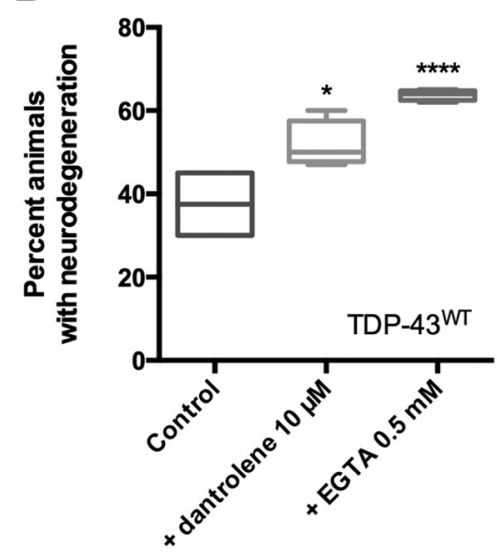

C

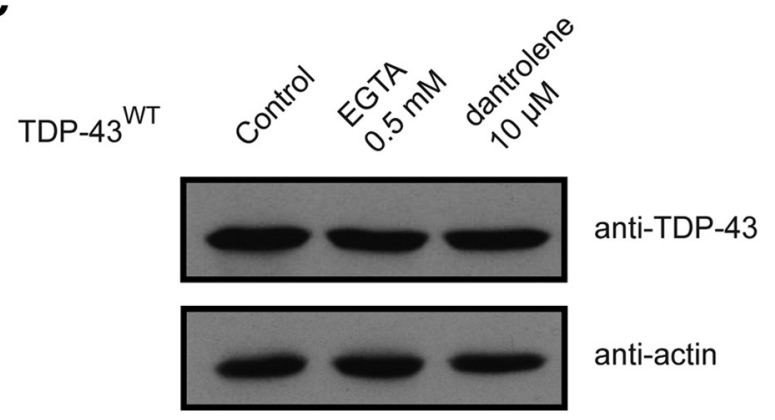

Figure 3. Disrupted $\mathrm{Ca}^{2+}$ homeostasis enhances wild-type TDP-43 toxicity. A, Transgenic worms expressing TDP- $43{ }^{\mathrm{WT}}$ treated with either EGTA or dantrolene had increased rates of paralysis compared with untreated controls ( $p<0.01$ for dantrolene-treated worms versus untreated TDP-43 ${ }^{\mathrm{WT}}$ controls; $p<0.0001$ for EGTA-treated worms versus untreated TDP-43 ${ }^{\mathrm{WT}}$ controls). TDP-43 ${ }^{\text {WT }}, n=90 ;$ TDP-43 ${ }^{\text {WT }}+$ dantrolene, $n=90 ;$ TDP-43 ${ }^{\text {WT }}+$ EGTA, $n=90$. B , Treatment with dantrolene or EGTA increased neurodegeneration in adults on day 9; TDP-43 ${ }^{\text {WT }}$ transgenics compared with untreated TDP- $43{ }^{\text {WT }}$ transgenics. ${ }^{*} p<0.05$ versus TDP- $43{ }^{\text {WT }}$ at day 9 , ${ }^{* * * *} p<0.0001$ versus TDP- $43{ }^{\text {WT }}$ at day 9 . C, Similar levels of TDP- 43 proteins were detected by Western blotting in untreated TDP-43 ${ }^{\mathrm{WT}}$ transgenics compared with animals treated with EGTA or dantrolene.

We previously reported that worms expressing mutant TDP43, but not wild-type TDP-43, show elevated ER and oxidative stress (Vaccaro et al., 2013). $\mathrm{Ca}^{2+}$ release and uptake is essential for normal cellular function, and we hypothesized that chemically manipulating $\left[\mathrm{Ca}^{2+}\right]_{\mathrm{i}}$ may only be beneficial to neurons expressing mutant TDP-43 if disrupted $\mathrm{Ca}^{2+}$ homeostasis is indeed an underlying mechanism of mutant TDP-43 toxicity. To explore this possibility, we tested transgenics expressing TDP$43^{\mathrm{WT}}$ with EGTA or dantrolene, and observed that exposure to either compound greatly enhanced paralysis and neurodegeneration (Fig. 3). Thus, chemically manipulating $\left[\mathrm{Ca}^{2+}\right]_{\mathrm{i}}$ is beneficial only to neurons expressing mutant TDP- 43 proteins.

Thapsigargin-induced ER $\mathrm{Ca}^{2+}$ release restores TDP- $43^{\mathrm{A} 315 \mathrm{~T}}$ dependent cell death in the absence of calreticulin

We next explored whether forced ER $\mathrm{Ca}^{2+}$ release might overcome the crt-1-induced block on TDP-43-mediated paralysis and neurodegeneration. Here, we sought to reverse $\mathrm{crt}$-1-dependent suppression of TDP-43 neuronal toxicity by driving release of the remaining $\mathrm{ER} \mathrm{Ca}^{2+}$ stores in TDP-43 ${ }^{\mathrm{A} 315 \mathrm{~T}}$; crt-1 (bz30) animals. We treated TDP- $43^{\mathrm{A} 315 \mathrm{~T}}$; crt-1(bz30) animals, which are fully suppressed for paralysis and neurodegeneration, with thapsigargin, a compound that inhibits the sarcoplasmic/endoplasmic reticulum $\mathrm{Ca}^{2+}$ ATPase (SERCA) ER $\mathrm{Ca}^{2+}$ reuptake pump and induces the release of ER $\mathrm{Ca}^{2+}$ via the InsP3 receptor channel (Takemura et al., 1989). We found that thapsigargin treatment significantly restored paralysis and neurodegeneration in TDP$43^{\mathrm{A} 315 \mathrm{~T}}$; crt-1(bz30) mutants compared with chemically untreated controls (Fig. 4A,B). As a positive control, we exposed transgenics expressing TDP- $43^{\mathrm{WT}}$ to thapsigargin, and we observed the enhancement of paralysis and neurodegeneration phenotypes (Fig. $4 A, B$ ), suggesting that increased $\left[\mathrm{Ca}^{2+}\right]_{\mathrm{i}}$ induces cellular damage in C. elegans. Finally, using immunoblotting we confirmed that treatment with thapsigargin did not affect the expression of TDP-43 transgenes (Fig. $4 C$ ). In summary, these data suggest that the elevation of $\left[\mathrm{Ca}^{2+}\right]_{\mathrm{i}}$ itself may be cytotoxic in nematode motor neurons, supporting a model in which a critical rise in $\left[\mathrm{Ca}^{2+}\right]_{\mathrm{i}}$ is a causative factor in neurotoxicity, and that CRT-1 is not required for thapsigargin-induced cell death.

\section{Calpain and aspartyl proteases are required for} neurodegeneration in a C. elegans ALS model

Caspase-dependent apoptosis is a major mechanism promoting cell death in neurodegenerative diseases (Fuchs and Steller, 2011). To determine whether apoptosis was involved in TDP-43 toxicity, we disrupted the main executioner protease, caspase CED-3, which mediates programmed cell death in C. elegans (Ellis and Horvitz, 1986). We observed that ced-3 was not required for paralysis or degenerative phenotypes induced by mutant TDP- $43^{\mathrm{A} 315 \mathrm{~T}}$ in motor neurons (Fig. $5 A, B$ ). Thus, having shown that genetic and pharmacological manipulation of $\left[\mathrm{Ca}^{2+}\right]_{i}$ suppresses neurotoxic effects of TDP- $43^{\mathrm{A} 315 \mathrm{~T}}$ in motor neurons, and based on the "calpain-cathepsin" hypothesis described previously (Yamashima et al., 1998), we investigated aspartyl and calpain protease function in paralysis and neurodegeneration. There are 17 genes with similarity to calpain, 7 of which show significant identity to mammalian calpains (Syntichaki et al., 2002), and 7 aspartyl protease genes encoded in the C. elegans 
genome (Tcherepanova et al., 2000). Based on previous work linking some of these genes to neurodegeneration in C. elegans (Syntichaki et al., 2002), as well as the availability of viable loss-of-function mutant strains, we focused on the $\mathrm{Ca}^{2+}$ regulated calpain protease TRA-3 and the aspartyl protease ASP-4. Furthermore, asp-4 has previously been identified as a modifier of $\alpha$-synuclein toxicity in C. elegans (Qiao et al., 2008). Using null mutants for tra-3 and asp-4, we scored for paralysis and neurodegeneration in strains expressing TDP-43 ${ }^{\mathrm{A} 315 \mathrm{~T}}$. We observed a significant reduction in the rate of paralysis and the progressive degeneration of motor neurons for TDP-43 ${ }^{\mathrm{A} 315 \mathrm{~T}}$; tra-3(ok2207) or TDP-43 ${ }^{\mathrm{A} 315 \mathrm{~T}}$; asp4(ok2693) animals compared with control TDP-43 ${ }^{\mathrm{A} 315 \mathrm{~T}}$ strains (Fig. $5 A, B$ ). To confirm that these calpain and aspartyl proteases acted downstream of elevated $\left[\mathrm{Ca}^{2+}\right]_{\mathrm{i}}$ to regulate mutant TDP-43 toxicity, we treated TDP-43 ${ }^{\mathrm{A} 315 \mathrm{~T}}$; tra3 (ok2207) and TDP-43 ${ }^{\mathrm{A} 315 \mathrm{~T}}$; asp4(ok2693) strains with thapsigargin. We observed that thapsigargin treatment failed to restore TDP-43 ${ }^{\mathrm{A} 315 \mathrm{~T}}$-induced paralysis and neurodegeneration when the calpain or aspartyl proteases were absent (Fig. 5C,D). These data suggest that tra-3 and asp-4 are essential for calcium-mediated neurotoxicity associated with mutant TDP-43, and that these proteases may be a terminal effector of neurodegeneration. Furthermore, TDP-43 transgene expression was not affected by mutations in ced-3, tra-3, or asp-4 (Fig. $5 E)$. We next wanted to determine whether the calpain-aspartyl protease pathway could be a target for small-molecule intervention against TDP-43 toxicity. Z-ValPhe-CHO (MDL-28170) is a calpain inhibitor previously shown to suppress necrosis in C. elegans (Syntichaki et al., 2002). We observed a significant reduction of TDP$43^{\mathrm{A} 315 \mathrm{~T}}$-mediated paralysis in worms treated with MDL-28170 (Fig. 5F). These data suggest that calpain and aspartyl proteases may be targeted for preventing neurodegeneration associated with mutant ALS proteins.

Cell-autonomous suppression of TDP-43 toxicity by tra-3 and asp-4 in motor neurons

We wondered whether the regulation of TDP-43 toxicity was specific to tra-3 and asp-4, or involved additional calpain and aspartyl proteases. Using RNAi, we conducted a blind screen of five calpain ( $c l p-1, c l p-2, c l p-4, c l p-7$, and tra-3) and seven aspartyl (asp-1, asp-3, asp-4, asp-6, asp-7, asp-10, and asp-13) protease genes against TDP-43 ${ }^{\mathrm{A} 315 \mathrm{~T}}$ transgenics engineered for RNAi sensitivity only within the nervous system (Calixto et al., 2010). We observed that RNAi against only tra-3 or asp-4 significantly suppressed the paralysis phenotype of TDP-43 ${ }^{\mathrm{A} 315 \mathrm{~T}}$ transgenics (Fig.
$6 A, B)$. In conjunction with our experiments using null mutants, our RNAi experiments suggest that the regulation of TDP$43^{\mathrm{A} 315 \mathrm{~T}}$ toxicity is specific to $\operatorname{tra}-3$ and $a s p-4$. We wondered whether the effects of $t r a-3$ and $a s p-4$ in mediating TDP-43 ${ }^{\mathrm{A} 315 \mathrm{~T}}$ motor defects were cell autonomous or cell nonautonomous. We conducted tra-3 or asp-4 RNAi experiments in TDP-43 ${ }^{\mathrm{A} 315 \mathrm{~T}}$ transgenics sensitized to RNAi only within intestinal cells or body wall muscle cells. We observed no significant reduction of paralysis by tra-3 or asp-4 RNAi targeted to intestinal or body wall muscle cells (Fig. 6C,D). These data suggest that motor defects and degenerative phenotypes caused by TDP- $43^{\mathrm{A} 315 \mathrm{~T}}$ require the activity of tra-3 and asp-4 in the nervous system, and are not likely to be influenced by protease activity in other tissues. Unfortu- 

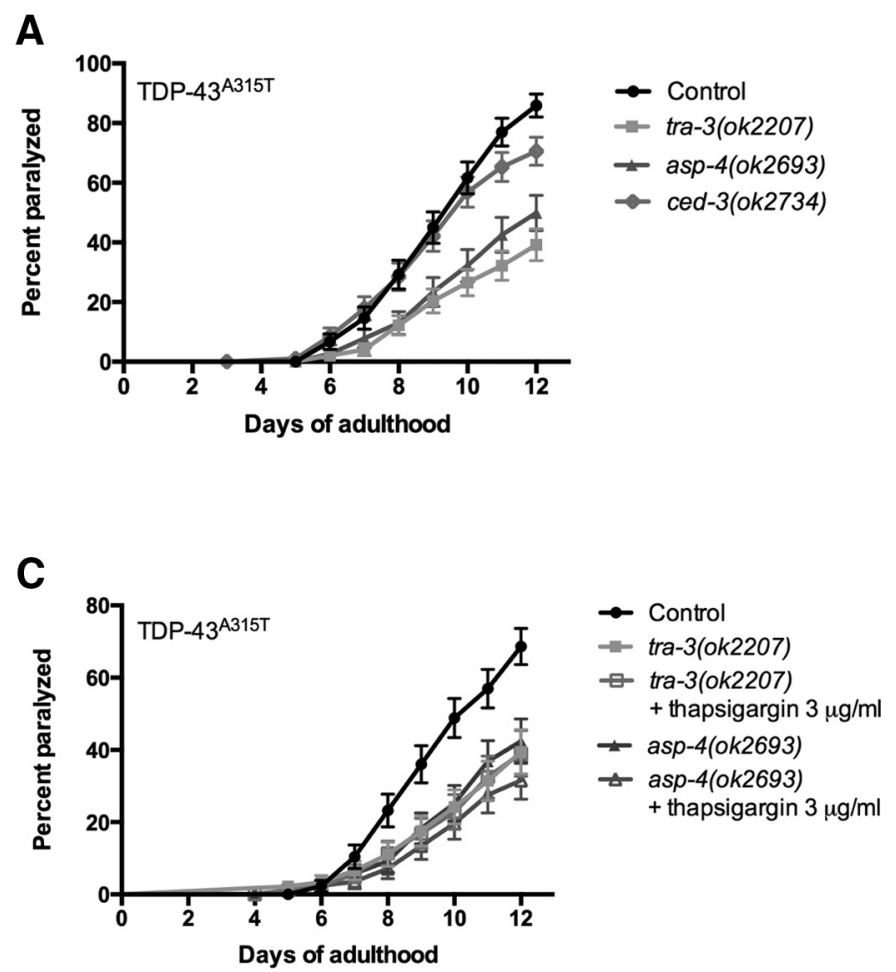

E

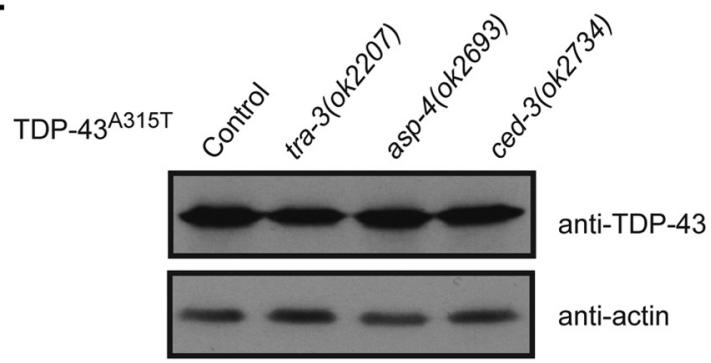

B

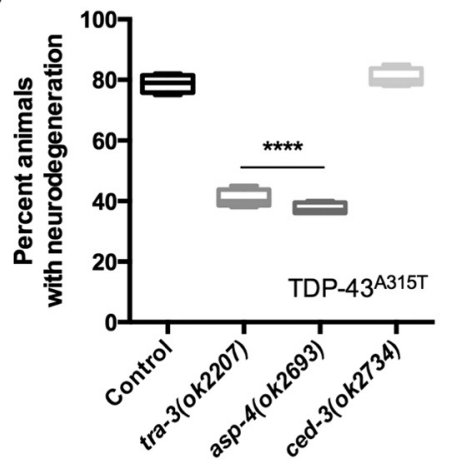

D

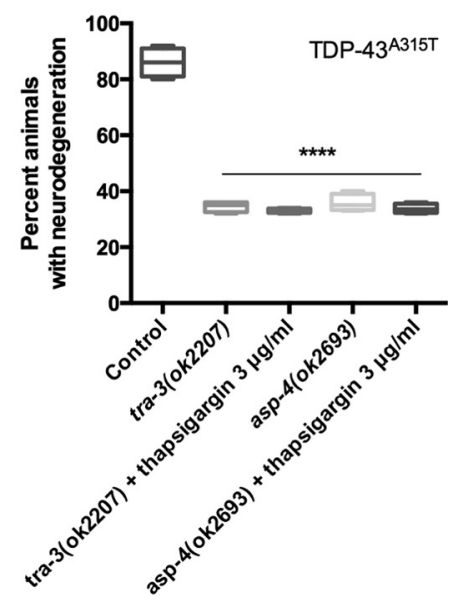

F

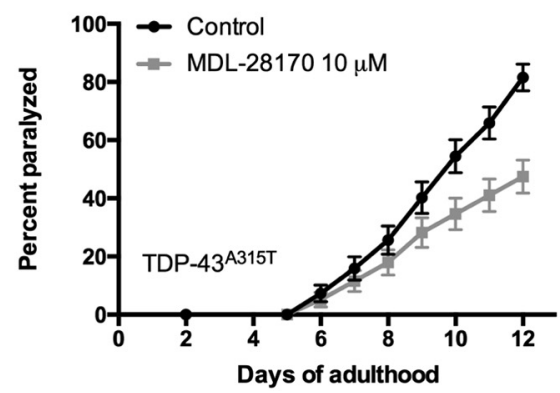

Figure 5. Calpain and aspartyl proteases facilitate TDP-43 neuronal toxicity. $\boldsymbol{A}$, Null mutations in tra-3 or asp-4 suppress age-dependent paralysis in TDP-43 ${ }^{\mathrm{A3} 15 \mathrm{~T}}$ transgenics compared with TDP-43 ${ }^{\mathrm{A} 315 \mathrm{~T}}$ controls. Mutation in ced-3 had no significant effect on paralysis phenotypes compared with TDP-43 ${ }^{\mathrm{A3} 15 \mathrm{~T}} . p<0.0001$ for TDP-43 ${ }^{\text {A315T; }}$; tra-3 (ok2207) or TDP-43 ${ }^{\text {A315T; }}$; asp-4(ok2693) versus TDP-43 ${ }^{\text {A315T }}$ transgenic controls. TDP-43 ${ }^{\text {A315T }}, n=90 ;$ TDP-43 ${ }^{\text {A315T; }}$;ra-3(ok2207), $n=102 ;$ TDP-43 ${ }^{\text {A315T }}$; asp-4(ok2693), $n=79 ;$ TDP-43 ${ }^{\text {A315T; }}$; ced-3(ok2734), $n=96 . \boldsymbol{B}$, Neurodegeneration was significantly reduced in adult, day 9 , TDP-43 $3^{\mathrm{A} 15 \mathrm{~T} T}$ transgenics by tra- 3 or asp-4 null mutations compared with TDP- $43^{\mathrm{A3} 15 \mathrm{~T}}$ alone. A null mutation of ced-3 failed to suppress TDP-43 $3^{\mathrm{A3} 15 \mathrm{~T}}$ neurodegeneration. ${ }^{* * *} p<0.0001$ versus TDP-43 ${ }^{\mathrm{A} 315 \mathrm{~T}}$ at day 9 . C, The suppression of TDP-43 ${ }^{\mathrm{A} 315 \mathrm{~T}}$-mediated paralysis by tra- 3 or asp- 4 was unaffected by the addition of thapsigargin. $p<$ 0.0001 for TDP-43 ${ }^{\mathrm{A} 315 \mathrm{~T}}$ versus TDP-43 ${ }^{\mathrm{A} 315 \mathrm{~T}}$; tra-3(ok2207) or TDP-43 ${ }^{\mathrm{A3} 15 \mathrm{~T}}$; asp-4(ok2693) with or without thapsigargin treatment. TDP-43 ${ }^{\mathrm{A3} 15 \mathrm{~T}}, n=90 ;$;DP-43 ${ }^{\mathrm{A3} 15 \mathrm{~T}} ;$ tra-3(ok2207), $n=90$; TDP-43 ${ }^{\text {A315T; }}$ tra-3(ok2207) + thapsigargin, $n=90 ;$ TDP-43 ${ }^{\text {A315T }}$; asp-4(ok2693), $n=90 ;$ TDP-43 $^{\text {A315T; }}$ asp-4(ok2693) + thapsigargin, $n=90$. D, Suppression of age-dependent neurodegeneration in TDP- $43^{\text {A315T }}$ transgenics by tra-3 or asp- 4 mutations was unchanged by thapsigargin treatment. ${ }^{* * * *} p<0.0001$ versus TDP- $43^{\text {A315T }}$ at day $9 . E$, Null mutations of tra-3, asp-4, or ced-3 did not affect TDP-43 protein expression. $\boldsymbol{F}$, The calpain inhibitor MDL-28170 reduced paralysis in TDP-43 ${ }^{\text {A315T }}$ transgenics. $p<0.001$ for treated versus untreated TDP-43 ${ }^{\text {A315T }}$ animals.

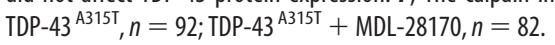

nately, we could not extend this analysis to $\mathrm{Ca}^{2+}$ homeostasis genes since crt-1 and itr-1 RNAi were ineffective in our assays.

$\mathrm{Ca}^{2+}$ homeostasis and protease genes do not suppress TDP$43^{\mathrm{WT}}$ motor defects

Since our primary assay to identify neuroprotective agents depends on a behavioral assay to detect improved motility of TDP-
$43^{\mathrm{A} 315 \mathrm{~T}}$ transgenics, there is the possibility that we may have identified mutants that nonspecifically augment motility phenotypes. To rule this out, we turned to our TDP- $43^{\mathrm{WT}}$ strains that show limited toxicity, with paralysis phenotypes comparable to the expression of GFP alone (Vaccaro et al., 2012a). We crossed itr-1(sa73), unc-68(e540), crt-1(bz30), cnx1(nr2010), tra-3(ok2207), or asp-4(ok2693) mutations into the 
A

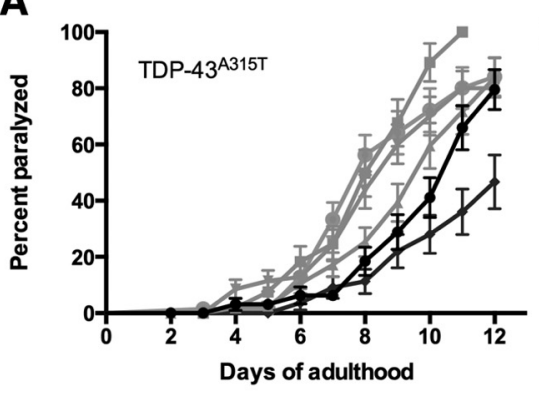

C

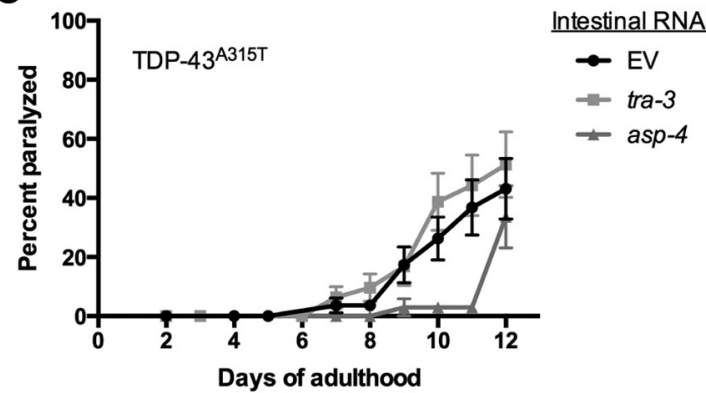

Neuronal RNAi

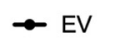

$-c / p-1$

$+c l p-2$

$\because c / p-4$

$\rightarrow$ tra-3

- clp-7
B

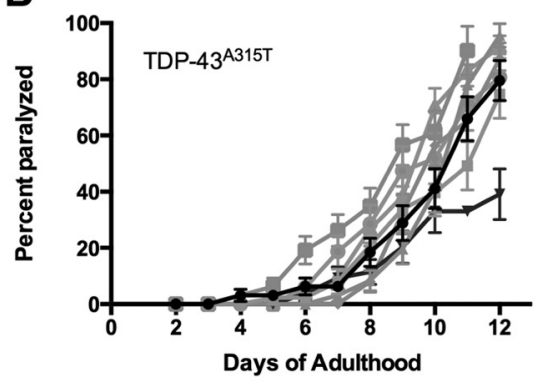

Neuronal RNAi

$\rightarrow$ EV

- asp-1

- asp-3

- $a s p-4$

$\sim$ asp-6

- asp-7

- $a s p-10$

- asp-13

$D$

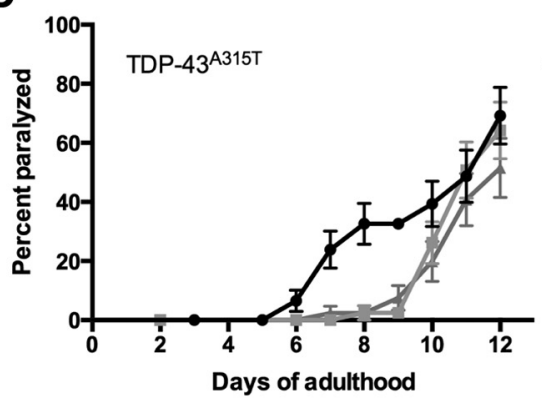

Body wall

muscle RNAi

$\sim \mathrm{EV}$

- tra-3

$-a s p-4$

Figure 6. TDP-43-mediated motility defects require tra- 3 and asp-4 in the nervous system. $A$, RNAi against tra-3 suppressed TDP- $43^{\text {A315T }}$-mediated paralysis. $p<0.05$ for TDP- $43^{\text {A315T }}$ treated

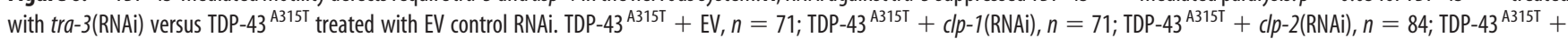

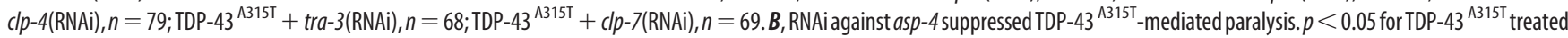

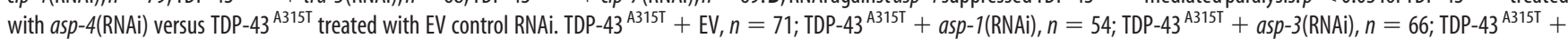
asp-4(RNAi), $n=67 ;$ TDP-43 $^{\text {A315T }}+$ asp-6(RNAi), $n=59 ;$ TDP-43 $^{\text {A315T }}+$ asp-7(RNAi), $n=62 ;$ TDP-43 $^{\text {A315T }}+$ asp-10(RNAi), $n=68 ;$ TDP-43 $^{\text {A315T }}+$ asp- 13 (RNAi), $n=58$. C, There were no significant differences in the rates of paralysis for TDP- $43^{\mathrm{A3} 15 \mathrm{~T}}$ sensitized for intestine-specific RNAi by treatment with EV(RNAi), tra-3(RNAi), or asp-4(RNAi). TDP-43 ${ }^{\mathrm{A3} 15 \mathrm{~T}}+\mathrm{EV}, n=77$; TDP-43 ${ }^{\text {A315T }}+$ tra-3(RNAi), $n=54 ;$ TDP-43 ${ }^{\text {A315T }}+$ asp-4(RNAi), $n=59$. D, There were no significant differences in the rates of paralysis for TDP-43 ${ }^{\text {A315T }}$ sensitized for body wall muscle-specific

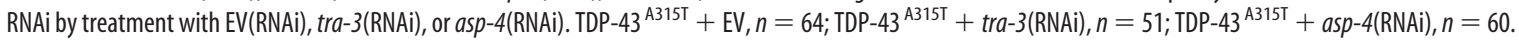

TDP-43 ${ }^{\mathrm{WT}}$ strain, but none of the mutations suppressed the paralysis phenotype caused by TDP-43 ${ }^{\mathrm{WT}}$ (Fig. 7). However, TDP-43 ${ }^{\mathrm{WT}}$; unc-68(e540) animals had a higher rate of paralysis compared with TDP-43 ${ }^{\mathrm{WT}}$ controls $(p<0.05)$, suggesting that a general impairment of UNC-68 function may negatively impact the neuronal function and motility observed in TDP- $43^{\mathrm{WT}}$ worms. Thus, we conclude that neuroprotective effects of these mutants against TDP- $43^{\mathrm{A} 315 \mathrm{~T}}$ toxicity are not due to a general improvement of motor function.

\section{Discussion}

$\mathrm{Ca}^{2+}$ homeostasis and ALS

$\mathrm{Ca}^{2+}$ is an intracellular signaling mole-

cule that regulates many mechanisms in the nervous system (Nikoletopoulou and Tavernarakis, 2012). Cells maintain a tightly controlled resting cytosolic free calcium concentration of $\sim 100$ nM by extruding excess $\mathrm{Ca}^{2+}$ by pumps and exchangers, and by compartmentalizing $\mathrm{Ca}^{2+}$. The ER is involved in many critical processes, including being a specialized $\mathrm{Ca}^{2+}$-storing organelle (100-800 $\mu \mathrm{M}$ range). The ER is closely involved in the regulation of $\mathrm{Ca}^{2+}$ flow within cells and is found in all neurons, occupying cell bodies, and extending toward axons, dendrites, and dendritic spines. In the context of ALS, evidence is mounting that the capacity of the cellular machinery of the ER to properly fold proteins is exceeded (Hetz and Mollereau, 2014), leading cells to react with the $\mathrm{UPR}^{\mathrm{ER}}$ and that a perturbation of the ER function can induce $\mathrm{Ca}^{2+}$ depletion. Studies investigating $\mathrm{Ca}^{2+}$ homeostasis in motor neurons have shown that ALS-vulnerable motor neurons in mice display low endogenous $\mathrm{Ca}^{2+}$ buffering capacities (Lips and Keller, 1998; Palecek et al., 1999). We hypothesized that dysregulated $\left[\mathrm{Ca}^{2+}\right]_{\mathrm{I}}$, possibly from the release of ER $\mathrm{Ca}^{2+}$ stores, may contribute to mutant TDP-43 neuronal toxicity.

We tested for potential influences of $\mathrm{Ca}^{2+}$ in mutant TDP$43^{\mathrm{A} 315 \mathrm{~T}}$-induced degeneration in the following two ways: with genetic mutations that alter release of $\mathrm{ER} \mathrm{Ca}^{2+}$ stores; and by using chemical reagents to manipulate $\mathrm{ER} \mathrm{Ca}^{2+}$ release (Fig. 8). We found that null mutations in $c r t-1$, a molecular chaperone that plays a critical and complex role in cellular calcium homeostasis as a major site for stored $\mathrm{Ca}^{2+}$ (Michalak et al., 1999), suppressed both paralysis and neurodegeneration induced by 

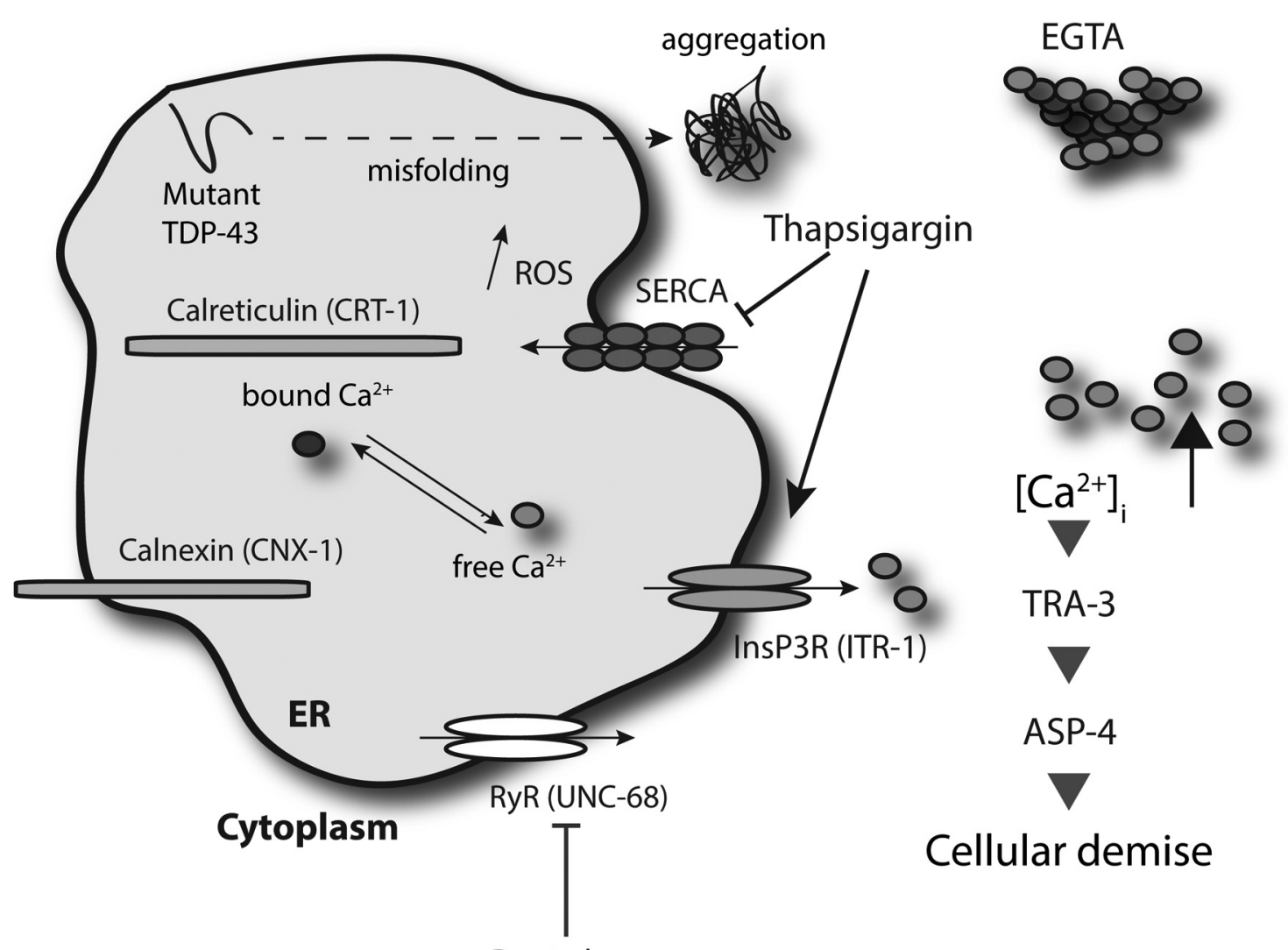

TRA-3

Dantrolene

Figure 8. Working model for TDP-43 and $\mathrm{Ca}^{2+}$-dependent necrosis-like neuronal toxicity. The chronic stress induced by protein misfolding and aggregation of mutant TDP-43 proteins may lead to inappropriate release of $\mathrm{Ca}^{2+}$ from ER stores into the cytoplasm. The resultant $\left[\mathrm{Ca}^{2+}\right]_{i}$ increase is essential for downstream events, including activation of the $\mathrm{Ca}^{2+}$-regulated TRA-3 calpain protease, which in turn mediates leakage of killer aspartyl proteases (ASP-4), leading to neuronal dysfunction and cell death. Mutations affecting ER $\mathrm{Ca}^{2+}$ storage (calreticulin and calnexin) or ER calcium release (InsP3R and RYR calcium release channels) disrupt release and are therefore neuroprotective. Pharmacological reduction of $\left[\mathrm{Ca}^{2+}\right]_{i}$ by EGTA or dantrolene is also neuroprotective, while a forced increase of $\left[\mathrm{Ca}^{2+}\right]_{i}$ by thapsigargin enhances neuronal toxicity. Disabling the activity of calpain or aspartyl proteases also protects against TDP-43-associated neuronal dysfunction and degeneration.

mutant TDP-43. Dysregulation of the ER-resident $\mathrm{Ca}^{2+}$ binding protein calreticulin may directly contribute to motor neuron death in ALS models (Bernard-Marissal et al., 2012). Our data showing that calreticulin contributes to neurodegeneration is somewhat at odds with findings for an SOD-1 model showing that reduced calreticulin levels activate the FAS/CD95 pathway to trigger cell death (Bernard-Marissal et al., 2012). However, no clear ortholog of FAS/CD95 exists in the C. elegans genome, suggesting that the role of calreticulin in mediating TDP-43 neuronal toxicity in our study may follow different cellular mechanisms. Alternatively, the mechanisms governing the degradation of SOD1 proteins may be distinct from TDP-43 (Mulligan and Chakrabartty, 2013).

However, ER stress has emerged as a mechanism in ALS (Matus et al., 2013; Tadic et al., 2014), and has been linked to the motor neuron vulnerability observed in SOD-1 mouse models (Nishitoh et al., 2008; Saxena et al., 2009), but it remains to be seen whether the ER is a site of action for other ALS mouse models. Furthermore, many aspects of the genetic signaling pathways controlling ER stress response were discovered in C. elegans and are conserved in mammalian systems (Mori, 2009). Encouragingly, we previously linked the ER stress response to TDP-43 toxicity (Vaccaro et al., 2013), and identified a number of small molecules that reduce neurodegeneration in $C$. elegans and zebrafish TDP-43 motor neuron models. Further insights into the induction of the ER stress response and neurodegeneration come from a recent report using a C. elegans model of SOD1 neuronal toxicity (Thompson et al., 2014). Linking the model organism studies to mammals are the ER stress-protective compounds salubrinal (Saxena et al., 2009) and guanabenz (Jiang et al., 2014), both of which show neuroprotective activity in mouse SOD-1 models. Thus, work from C. elegans models may be predictive for mechanisms of motor neuron degeneration in mammalian systems.

Because luminal calreticulin works in conjunction with calnexin to effectuate chaperone functions and mediate cellular $\mathrm{Ca}^{2+}$ homeostasis (Krause and Michalak, 1997), we also disrupted calnexin function using loss-of-function mutations and confirmed the suppression of TDP-43 neuronal toxicity. It is known that $\mathrm{Ca}^{2+}$ is released from ER stores into the cytoplasm via the InsP3R and the RyR $\mathrm{Ca}^{2+}$ channels. We blocked the RyR function by using a null mutation in $u n c-68$ or by treatment with dantrolene, a reagent that specifically inhibits $\mathrm{Ca}^{2+}$ release from ER stores (Song et al., 1993), and InsP3R by using a null mutation in $i t r-1$, and we showed the same suppression of TDP-43 toxicity. Thus, our data extend upon and are consistent with recent work showing that inositol triphosphate receptors regulate neurotoxicity in Drosophila and cell culture TDP-43 models (Kim et al., 2012). Further highlighting the role of $\mathrm{Ca}^{2+}$ homeostasis, treatment of TDP-43 ${ }^{\mathrm{A} 315 \mathrm{~T}}$ mutants with EGTA, a $\mathrm{Ca}^{2+}$ specific chelator, produced a clear reduction of paralysis and neurodegeneration phenotypes. Importantly, the fact that nei- 
ther dantrolene nor EGTA enhanced TDP-43 toxicity in TDP$43^{\mathrm{A} 315 \mathrm{~T}}$; crt-1 or TDP- $43^{\mathrm{A} 315 \mathrm{~T}}$; itr-1 double mutants suggests that the inappropriate release of $\mathrm{Ca}^{2+}$ from ER stores may be a common mechanism of TDP-43-mediated neuronal toxicity. Conversely, thapsigargin-induced $\mathrm{ER} \mathrm{Ca}^{2+}$ release, by activating the InsP3R function and blocking the $\mathrm{Ca}^{2+}$ return to the ER from the cytoplasm via the SERCA Ca ${ }^{2+}$ pump, can restore TDP- $43^{\mathrm{A} 315 \mathrm{~T}}$ induced cell death in the absence of calreticulin, indicating that $\mathrm{Ca}^{2+}$ release and uptake are essential for TDP-43 ${ }^{\mathrm{A} 315 \mathrm{~T}}$ neuronal toxicity, and can in fact also enhance the toxicity of worms expressing TDP- $43^{\mathrm{WT}}$ in motor neurons.

The role of endogenous TDP-1/TDP-43 in neurodegeneration Our group (Vaccaro et al., 2012b), plus another research team (Zhang et al., 2012), previously reported that endogenous TDP-1 (C. elegans ortholog of TDP-43) is required for toxicity caused by the transgenic expression of mutant TDP-43 in the C. elegans nervous system. Additionally, we also showed that TDP-1/ TDP-43 is required for the toxicity of mutant polyglutamine proteins in $C$. elegans and mammalian cell culture models of Huntington's disease (Tauffenberger et al., 2013). These findings suggest that wild-type TDP-1/TDP-43 may actively contribute to neurodegeneration beyond ALS. Our previous work also showed that $t d p-1$ is ubiquitously expressed, and is mainly a nuclear protein. Under stress conditions, including ER stress, TDP-1 expression is increased, and this chronic, elevated expression is cytotoxic, leading to decreased lifespan in worms (Vaccaro et al., 2012b). These observations are consistent with the function of TDP-43 as a stress-inducible protein, as is seen in many systems (Janssens and Van Broeckhoven, 2013). Another conserved phenotype of TDP-43 is its cytotoxicity when overexpressed, suggesting that its expression levels are tightly regulated (Buratti and Baralle, 2011). A caveat of our data interpretation in this current study is that a role for TDP-1 in the necrosis-like degeneration of TDP- $43^{\mathrm{A} 315 \mathrm{~T}}$ motor neurons was not examined. Part of the cascade of molecular events described here leading to neurodegeneration may involve endogenous TDP-1. The cytotoxicity of TDP-1 itself may depend on $\mathrm{Ca}^{2+}$ homeostasis and/or protease genes. Additionally, since TDP-1 is a DNA/RNA binding protein, another possibility is that TDP-1 may regulate the expression of $\mathrm{Ca}^{2+}$ and protease genes under stress conditions, including for proteotoxicity and ER stress. Future studies will explore the contribution of TDP-1 to these molecular mechanisms.

Necroptosis as a key mechanism of neurodegeneration in ALS The perturbation of cytosolic $\mathrm{Ca}^{2+}$ homeostasis has been implicated in necrotic cell death both in mammals and in C. elegans (Sattler and Tymianski, 2000; Xu et al., 2001), but the mechanism by which $\mathrm{Ca}^{2+}$ triggers cellular demise remains unclear; so, we investigated relevant signaling pathways based upon the "calpain-cathepsin hypothesis." In 1998, Yamashima et al. formulated the calpain-cathepsin hypothesis, according to which $\mathrm{Ca}^{2+}$-activated cysteine proteases compromise the integrity of the lysosome and cause leakage of acidic hydrolases (Yamashima et al., 1998). We tested the requirement for calpain and aspartyl protease activity in neurodegeneration inflicted by the expression of TDP-43 ${ }^{\mathrm{A} 315 \mathrm{~T}}$ in GABAergic motor neurons, and showed that null mutations in the calcium-regulated tra-3 calpain protease and aspartyl protease asp-4 suppress both paralysis and neurodegeneration. Interestingly, TDP-43 ${ }^{\mathrm{A} 315 \mathrm{~T}}$ toxicity was unaffected by a null mutation in the cysteine-aspartate protease CED-3, a protein central to apoptosis in C. elegans, and in agreement with previous studies of TDP-43 toxicity in C. elegans (Liachko et al.,
2010). Thus, in terms of genetic signaling pathways the neuronal toxicity caused by TDP-43 ${ }^{\mathrm{A} 315 \mathrm{~T}}$ in C. elegans more closely resembles necrosis than classic apoptosis (Troulinaki and Tavernarakis, 2012).

Recent work has suggested that motor neuron death in models of both sporadic and familial ALS occurs through necroptosis ( Re et al., 2014), a form of programmed necrosis that does not require caspases (Ofengeim and Yuan, 2013). Our work is in agreement with this notion as inactivation of a $C$. elegans key executioner caspase, ced-3, had no effect on motor neuron dysfunction in our TDP-43 models. Key molecules regulating necroptosis in ALS models include the receptor-interacting serine/threonineprotein kinase 1 and mixed-lineage kinase domain-like, but whether orthologs of these proteins regulate TDP-43 toxicity in our C. elegans ALS models requires further investigation. Importantly, work from C. elegans detailing programmed necrosis may shed light on mechanisms relevant to neurodegeneration in mammalian settings and perhaps specifically ALS.

Abnormal $\mathrm{Ca}^{2+}$ signaling has been linked to multiple neurological disorders, but the challenge remains in identifying disease-specific mechanisms (Bezprozvanny, 2009). We propose that the chronic stress induced by misfolded mutant TDP-43 proteins induces the inappropriate release of $\mathrm{Ca}^{2+}$ from ER stores into the cytoplasm is a trigger for subsequent neurodegeneration (Fig. 8). Disrupted $\mathrm{Ca}^{2+}$ homeostasis may have multiple downstream, effector mechanisms promoting neuronal dysfunction and cell death, including the inappropriate activation of the $\mathrm{Ca}^{2+}$-dependent proteases identified here, disrupting mitochondrial activity (Tradewell et al., 2011; Parone et al., 2013), or altered $\mathrm{Ca}^{2+}$ signaling at the neuromuscular junction (Armstrong and Drapeau, 2013). Thus, restoration of $\mathrm{Ca}^{2+}$ homeostasis in ALS motor neurons and/or limiting programmed necrosis may be pursued as potential therapeutic interventions.

\section{References}

Armstrong GA, Drapeau P (2013) Calcium channel agonists protect against neuromuscular dysfunction in a genetic model of TDP-43 mutation in ALS. J Neurosci 33:1741-1752. CrossRef Medline

Bernard-Marissal N, Moumen A, Sunyach C, Pellegrino C, Dudley K, Henderson CE, Raoul C, Pettmann B (2012) Reduced calreticulin levels link endoplasmic reticulum stress and Fas-triggered cell death in motoneurons vulnerable to ALS. J Neurosci 32:4901-4912. CrossRef Medline

Bezprozvanny I (2009) Calcium signaling and neurodegenerative diseases. Trends Mol Med 15:89-100. CrossRef Medline

Blokhuis AM, Groen EJ, Koppers M, van den Berg LH, Pasterkamp RJ (2013) Protein aggregation in amyotrophic lateral sclerosis. Acta Neuropathol 125:777-794. CrossRef Medline

Buratti E, Baralle FE (2011) TDP-43: new aspects of autoregulation mechanisms in RNA binding proteins and their connection with human disease. FEBS J 278:3530-3538. CrossRef Medline

Burdakov D, Verkhratsky A (2006) Biophysical re-equilibration of Ca2+ fluxes as a simple biologically plausible explanation for complex intracellular $\mathrm{Ca} 2+$ release patterns. FEBS Lett 580:463-468. CrossRef Medline

Calixto A, Chelur D, Topalidou I, Chen X, Chalfie M (2010) Enhanced neuronal RNAi in C. elegans using SID-1. Nat Methods 7:554-559. CrossRef Medline

Dal Santo P, Logan MA, Chisholm AD, Jorgensen EM (1999) The inositol trisphosphate receptor regulates a 50 -second behavioral rhythm in C. elegans. Cell 98:757-767. CrossRef Medline

Ellis HM, Horvitz HR (1986) Genetic control of programmed cell death in the nematode C. elegans. Cell 44:817-829. CrossRef Medline

Fuchs Y, Steller H (2011) Programmed cell death in animal development and disease. Cell 147:742-758. CrossRef Medline

Hetz C, Mollereau B (2014) Disturbance of endoplasmic reticulum proteostasis in neurodegenerative diseases. Nat Rev Neurosci 15:233-249. CrossRef Medline

Janssens J, Van Broeckhoven C (2013) Pathological mechanisms underlying TDP-43 driven neurodegeneration in FTLD-ALS spectrum disorders. Hum Mol Genet 22:R77-R87. CrossRef Medline 
Jiang HW, Ren M, Jiang HZ, Wang J, Zhang J, Yin X, Wang SY, Qi Y, Wang XD, Feng HL (2014) Guanabenz delays the onset of disease symptoms, extends lifespan, improves motor performance and attenuates motor neuron loss in the SOD1 G93A mouse model of amyotrophic lateral sclerosis. Neuroscience 277C:132-138. CrossRef Medline

Kabashi E, Valdmanis PN, Dion P, Spiegelman D, McConkey BJ, Vande Velde C, Bouchard JP, Lacomblez L, Pochigaeva K, Salachas F, Pradat PF, Camu W, Meininger V, Dupre N, Rouleau GA (2008) TARDBP mutations in individuals with sporadic and familial amyotrophic lateral sclerosis. Nat Genet 40:572-574. CrossRef Medline

Kim SH, Zhan L, Hanson KA, Tibbetts RS (2012) High-content RNAi screening identifies the Type 1 inositol triphosphate receptor as a modifier of TDP-43 localization and neurotoxicity. Hum Mol Genet 21:48454856. CrossRef Medline

Krause KH, Michalak M (1997) Calreticulin. Cell 88:439-443. CrossRef Medline

Liachko NF, Guthrie CR, Kraemer BC (2010) Phosphorylation promotes neurotoxicity in a Caenorhabditis elegans model of TDP-43 proteinopathy. J Neurosci 30:16208-16219. CrossRef Medline

Lips MB, Keller BU (1998) Endogenous calcium buffering in motoneurones of the nucleus hypoglossus from mouse. J Physiol 511:105-117. CrossRef Medline

Martin JB (1999) Molecular basis of the neurodegenerative disorders. N Engl J Med 340:1970-1980. CrossRef Medline

Maryon EB, Coronado R, Anderson P (1996) unc-68 encodes a ryanodine receptor involved in regulating C. elegans body-wall muscle contraction. J Cell Biol 134:885-893. CrossRef Medline

Matus S, Valenzuela V, Medinas DB, Hetz C (2013) ER dysfunction and protein folding stress in ALS. Int J Cell Biol 2013:674751. CrossRef Medline

Michalak M, Corbett EF, Mesaeli N, Nakamura K, Opas M (1999) Calreticulin: one protein, one gene, many functions. Biochem J 344:281-292. CrossRef Medline

Mori K (2009) Signalling pathways in the unfolded protein response: development from yeast to mammals. J Biochem 146:743-750. CrossRef Medline

Mulligan VK, Chakrabartty A (2013) Protein misfolding in the late-onset neurodegenerative diseases: common themes and the unique case of amyotrophic lateral sclerosis. Proteins 81:1285-1303. CrossRef Medline

Nikoletopoulou V, Tavernarakis N (2012) Calcium homeostasis in aging neurons. Front Genet 3:200. CrossRef Medline

Nishitoh H, Kadowaki H, Nagai A, Maruyama T, Yokota T, Fukutomi H, Noguchi T, Matsuzawa A, Takeda K, Ichijo H (2008) ALS-linked mutant SOD1 induces ER stress- and ASK1-dependent motor neuron death by targeting Derlin-1. Genes Dev 22:1451-1464. CrossRef Medline

Ofengeim D, Yuan J (2013) Regulation of RIP1 kinase signalling at the crossroads of inflammation and cell death. Nat Rev Mol Cell Biol 14:727736. CrossRef Medline

Palecek J, Lips MB, Keller BU (1999) Calcium dynamics and buffering in motoneurones of the mouse spinal cord. J Physiol 520:485-502. CrossRef Medline

Parone PA, Da Cruz S, Han JS, McAlonis-Downes M, Vetto AP, Lee SK, Tseng E, Cleveland DW (2013) Enhancing mitochondrial calcium buffering capacity reduces aggregation of misfolded SOD1 and motor neuron cell death without extending survival in mouse models of inherited amyotrophic lateral sclerosis. J Neurosci 33:4657-4671. CrossRef Medline

Qiao L, Hamamichi S, Caldwell KA, Caldwell GA, Yacoubian TA, Wilson S, Xie ZL, Speake LD, Parks R, Crabtree D, Liang Q, Crimmins S, Schneider L, Uchiyama Y, Iwatsubo T, Zhou Y, Peng L, Lu Y, Standaert DG, Walls $\mathrm{KC}$, et al. (2008) Lysosomal enzyme cathepsin D protects against alphasynuclein aggregation and toxicity. Mol Brain 1:17. CrossRef Medline

Re DB, Le Verche V, Yu C, Amoroso MW, Politi KA, Phani S, Ikiz B, Hoffmann L, Koolen M, Nagata T, Papadimitriou D, Nagy P, Mitsumoto H, Kariya S, Wichterle H, Henderson CE, Przedborski S (2014) Necroptosis drives motor neuron death in models of both sporadic and familial ALS. Neuron 81:1001-1008. CrossRef Medline

Renton AE, Chiò A, Traynor BJ (2014) State of play in amyotrophic lateral sclerosis genetics. Nat Neurosci 17:17-23. CrossRef Medline

Sattler R, Tymianski M (2000) Molecular mechanisms of calciumdependent excitotoxicity. J Mol Med 78:3-13. CrossRef Medline

Saxena S, Cabuy E, Caroni P (2009) A role for motoneuron subtype- selective ER stress in disease manifestations of FALS mice. Nat Neurosci 12:627-636. CrossRef Medline

Song SK, Karl IE, Ackerman JJ, Hotchkiss RS (1993) Increased intracellular $\mathrm{Ca} 2+$ : a critical link in the pathophysiology of sepsis? Proc Natl Acad Sci U S A 90:3933-3937. CrossRef Medline

Stiernagle T (2006) Maintenance of C. elegans. WormBook:1-11. Medline

Syntichaki P, Xu K, Driscoll M, Tavernarakis N (2002) Specific aspartyl and calpain proteases are required for neurodegeneration in C. elegans. Nature 419:939-944. CrossRef Medline

Tadic V, Prell T, Lautenschlaeger J, Grosskreutz J (2014) The ER mitochondria calcium cycle and ER stress response as therapeutic targets in amyotrophic lateral sclerosis. Front Cell Neurosci 8:147. CrossRef Medline

Takemura H, Hughes AR, Thastrup O, Putney JW Jr (1989) Activation of calcium entry by the tumor promoter thapsigargin in parotid acinar cells. Evidence that an intracellular calcium pool and not an inositol phosphate regulates calcium fluxes at the plasma membrane. J Biol Chem 264: 12266-12271. Medline

Tauffenberger A, Chitramuthu BP, Bateman A, Bennett HP, Parker JA (2013) Reduction of polyglutamine toxicity by TDP-43, FUS and progranulin in Huntington's disease models. Hum Mol Genet 22:782-794. CrossRef Medline

Tcherepanova I, Bhattacharyya L, Rubin CS, Freedman JH (2000) Aspartic proteases from the nematode Caenorhabditis elegans. Structural organization and developmental and cell-specific expression of asp-1. J Biol Chem 275:26359-26369. CrossRef Medline

Thompson ML, Chen P, Yan X, Kim H, Borom AR, Roberts NB, Caldwell KA, Caldwell GA (2014) TorsinA rescues ER-associated stress and locomotive defects in C. elegans models of ALS. Dis Model Mech 7:233-243. CrossRef Medline

Tradewell ML, Cooper LA, Minotti S, Durham HD (2011) Calcium dysregulation, mitochondrial pathology and protein aggregation in a culture model of amyotrophic lateral sclerosis: mechanistic relationship and differential sensitivity to intervention. Neurobiol Dis 42:265-275. CrossRef Medline

Troulinaki K, Tavernarakis N (2012) Endocytosis and intracellular trafficking contribute to necrotic neurodegeneration in C. elegans. EMBO J 31: 654-666. CrossRef Medline

Vaccaro A, Tauffenberger A, Aggad D, Rouleau G, Drapeau P, Parker JA (2012a) Mutant TDP-43 and FUS cause age-dependent paralysis and neurodegeneration in C. elegans. PLoS One 7:e31321. CrossRef Medline

Vaccaro A, Tauffenberger A, Ash PE, Carlomagno Y, Petrucelli L, Parker JA (2012b) TDP-1/TDP-43 regulates stress signaling and age-dependent proteotoxicity in Caenorhabditis elegans. PLoS Genet 8:e1002806. CrossRef Medline

Vaccaro A, Patten SA, Aggad D, Julien C, Maios C, Kabashi E, Drapeau P, Parker JA (2013) Pharmacological reduction of ER stress protects against TDP-43 neuronal toxicity in vivo. Neurobiol Dis 55:64-75. CrossRef Medline

Vanselow BK, Keller BU (2000) Calcium dynamics and buffering in oculomotor neurones from mouse that are particularly resistant during amyotrophic lateral sclerosis (ALS)-related motoneurone disease. J Physiol 525:433-445. CrossRef Medline

von Lewinski F, Fuchs J, Vanselow BK, Keller BU (2008) Low Ca2+ buffering in hypoglossal motoneurons of mutant SOD1 (G93A) mice. Neurosci Lett 445:224-228. CrossRef Medline

Walker AK, Atkin JD (2011) Stress signaling from the endoplasmic reticulum: a central player in the pathogenesis of amyotrophic lateral sclerosis. IUBMB Life 63:754-763. CrossRef Medline

Wijesekera LC, Leigh PN (2009) Amyotrophic lateral sclerosis. Orphanet J Rare Dis 4:3. CrossRef Medline

Xu K, Tavernarakis N, Driscoll M (2001) Necrotic cell death in C. elegans requires the function of calreticulin and regulators of $\mathrm{Ca}(2+)$ release from the endoplasmic reticulum. Neuron 31:957-971. CrossRef Medline

Yamashima T, Kohda Y, Tsuchiya K, Ueno T, Yamashita J, Yoshioka T, Kominami E (1998) Inhibition of ischaemic hippocampal neuronal death in primates with cathepsin B inhibitor CA-074: a novel strategy for neuroprotection based on 'calpain-cathepsin hypothesis'. Eur J Neurosci 10: 1723-1733. CrossRef Medline

Zhang T, Hwang HY, Hao H, Talbot C Jr, Wang J (2012) Caenorhabditis elegans RNA-processing protein TDP-1 regulates protein homeostasis and life span. J Biol Chem 287:8371-8382. CrossRef Medline 